\title{
A window to the future of liver surgery: a brave new world!
}

\author{
Vassilios Tsioukas ${ }^{1}$, Georgios Tsoulfas ${ }^{2}$ \\ ${ }^{1}$ School of Rural and Surveying Engineering, Aristotle University of Thessaloniki, Thessaloniki, Greece; ${ }^{2}$ Department of Transplantation Surgery, \\ Aristotle University School of Medicine, Aristotle University of Thessaloniki, Thessaloniki, Greece \\ Correspondence to: Georgios Tsoulfas, MD, PhD, FACS. Associate Professor of Transplantation Surgery, Chief Department of Transplantation \\ Surgery, Aristotle University School of Medicine, Aristotle University of Thessaloniki, Thessaloniki 54124, Greece. Email: tsoulfasg@auth.gr. \\ Comment on: Huettl F, Saalfeld P, Hansen C, et al. Virtual reality and 3D printing improve preoperative visualization of 3D liver reconstructions- \\ results from a preclinical comparison of presentation modalities and user's preference. Ann Transl Med 2021;9:1074.
}

Submitted Aug 28, 2021. Accepted for publication Sep 08, 2021.

doi: $10.21037 / \mathrm{atm}-21-4527$

View this article at: https://dx.doi.org/10.21037/atm-21-4527

The paper "Virtual reality and 3D printing improve preoperative visualization of $3 \mathrm{D}$ liver reconstructionsresults from a preclinical comparison of presentation modalities and user's preference" by Huettl et al. (1) seeks to draw safe conclusions about what is the preferred method for the presentation of patient's 3D liver model that could be used to identify the anatomy and delineate a tumor lesion by a physician.

The research uses a satisfactory statistical sample of both patients' cases and of experienced and nonexperienced physicians (doctors and medical students) who are invited to get acquainted with the models of the livers and to recognize on the virtual, printed and PDF 3D model a lesion of a cancerous tumor. Additionally, special questionnaires are filled out by the participating physicians and their opinions are gathered to identify which is the best presentation modality for future use at a clinical level.

For all three cases of presentation modality, the digital $3 \mathrm{D}$ liver model from numerous patients and through appropriate technology and equipment the same digital model is rendered, with the use of specialized software and appropriate tomography images:

(I) As a virtual model in a virtual reality (VR) system;

(II) As a 3D-printed transparent model with appropriate production in a unique object with different colors and materials of both the parenchyma, but also of the vessels and its tumors;

(III) As a 3D PDF file displayed on a common screen of a personal computer that through its rotation and the $2.5 \mathrm{D}$ (or pseudo-3D) viewing technique, it can be examined properly;
(IV) The final conclusions are undoubtable based on the measurable and objective indicators applied both in the time required for the recognition of liver damage by the participating physicians, but mainly by the success of the experienced and nonexperienced people in recognizing the correct position of the tumor in the liver based on its Couinaud segmentation.

One could say that the results obtained are rational, but this is not enough to justify the correctness and accuracy of the results of a scientific study. The results of the statistical analysis are thoroughly analyzed, and convincing explanations are given that justify the final verdict that makes VR more appropriate for its future application at the clinical level in the planning of liver surgeries and in the educational process.

According to the authors, the next step will be to apply a similar research method at the clinical level, i.e., to apply the three different modalities for identifying the location of the tumor at the preoperative level and the planning/preparing of an operation. However, it is not possible to use indicators of the precise location of the tumor or the time required to identify it within the parenchyma mass and, of course, it is not possible for many different treating physicians to perform the same test. However, several other indicators might be applicable such as recovery time inside or outside the Intensive Care Unit after surgery, interoperative blood loss, etc. Finally, in terms of cost and implementation time, the ability/impossibility of performing the different presentation modality methods and presenting a diseased liver are discussed, which is also important since the VR and 
PR application requires appropriate equipment and/or extra time to produce the $3 \mathrm{D}$ model.

The most important feature of this paper is that it represents a critical step in the effort to integrate new technological methods to achieve three basic aspects of liver, and by extension several other types of, surgery. Specifically, the use of the different imaging modalities can help improve (I) the training of medical students, surgical residents and fellows in a very demanding type of surgery, (II) provide crucial information to the patient and the family so that informed consent can be obtained regarding the upcoming surgery, and (III) the ability of the surgical team to conduct a more focused and precise surgical procedure. This is especially important if we consider the demanding nature of liver surgery, where there can be significant morbidity and even mortality. The application of these novel technologies will allow for a more targeted approach during the resection, which translates into decreased blood loss and improved recovery for the patient.

The challenge lies for all of us to acknowledge the fact that in order to achieve these results, there is a need for cross-disciplinary collaboration so that surgeons can understand the endless possibilities that are presented to them, but also learn to use them in a judicious manner. Given the amazing speed of technological evolution and the prospects presented to us by using technologies such as $3 \mathrm{D}$ printing, VR and, one should not forget, artificial intelligence, we can clearly see that hepatic surgery will undergo a major transformation in the not-sodistant future. However, it is also incumbent upon us to understand the limitations of these technologies, whether that has to do with cost, applicability, ethical and legal issues, and identify how to best apply them in the care of our patients and the education of our medical students, residents and fellows. The end result will be a major step towards achieving the goals of precision medicine and ensuring quality care.

Cite this article as: Tsioukas V, Tsoulfas G. A window to the future of liver surgery: a brave new world! Ann Transl Med 2021;9(19):1509. doi: 10.21037/atm-21-4527

\section{Acknowledgments}

Funding: None.

\section{Footnote}

Provenance and Peer Review: This article was commissioned by the editorial office, Annals of Translational Medicine. The article did not undergo external peer review.

Conflicts of Interest: Both authors have completed the ICMJE uniform disclosure form (available at https://dx.doi. org/10.21037/atm-21-4527). The authors have no conflicts of interest to declare.

Etbical Statement: The authors are accountable for all aspects of the work in ensuring that questions related to the accuracy or integrity of any part of the work are appropriately investigated and resolved.

Open Access Statement: This is an Open Access article distributed in accordance with the Creative Commons Attribution-NonCommercial-NoDerivs 4.0 International License (CC BY-NC-ND 4.0), which permits the noncommercial replication and distribution of the article with the strict proviso that no changes or edits are made and the original work is properly cited (including links to both the formal publication through the relevant DOI and the license). See: https://creativecommons.org/licenses/by-nc-nd/4.0/.

\section{References}

1. Huettl F, Saalfeld P, Hansen C, et al. Virtual reality and $3 \mathrm{D}$ printing improve preoperative visualization of $3 \mathrm{D}$ liver reconstructions-results from a preclinical comparison of presentation modalities and user's preference. Ann Transl Med 2021;9:1074. 